\title{
Public attitudes toward vaccination
}

\author{
Kelsey 0'Hagan-Wong \\ (McGill University) \\ News Reporter (HSI 2013-2014)
}

When asked about her attitude toward vaccines, Stephanie Cabildo, a 23-year-old criminology student at York University, responded "I don't think they are necessary." This is consistent with the trend that Dr. Brian Ward, a physician and leading expert in vaccine research at McGill University, has been noticing among the general and scientific communities with regards to vaccine efficacy and safety. "There has been an absolutely massive loss of confidence in vaccines over the last 20 years," he states.

Not surprisingly, this loss of confidence in vaccination has also translated into a decrease in the administration of childhood vaccines. The Center for Disease Control and Prevention recommends that children between the ages of 2-6 years receive 10 vaccinations that protect against 14 different diseases. ${ }^{1}$ Canada's current immunization rate is at roughly $84 \%$, which is below the recommended rate of $92 \%$ that is set by the World Health Organization that is needed to stop the spread of diseases in children. ${ }^{2}$ Although the national average is $84 \%$, there are some schools - for example, those in Lethbridge, Alberta - that have vaccination rates as low as $60 \% .^{3}$ In response to the striking decline in vaccine use, Dr. Ward states, "This is a potential disaster."

In fact, we are already starting to see the re-appearance of diseases that were presumed to have been eradicated in North America due to childhood vaccination schedules. In 2010, there was an outbreak of pertussis, more commonly known as the whooping cough, with nearly 10000 cases reported in California that killed 10 infants. ${ }^{4}$ In Canada, there were roughly 2000 cases reported (including the death of one infant) from coast to coast - from British Columbia's Fraser Valley, to southern Alberta, to parts of Southwestern Ontario, and to New Brunswick. ${ }^{5}$ Vaccination is not mandatory in Canada and recent reports suggest that the areas with the highest vaccine opt-outs are also those that experienced the most severe outbreaks. ${ }^{4}$

But why have people's attitudes towards immunization changed? Dr. Ward believes that, over the last ten years, the increasingly large amounts of non-science based information against vaccines available online, in tandem with the negative press regarding their safety, are to blame. The measles, mumps, and rubella (MMR) vaccine in particular has received a striking amount of notoriety. In 1998, the medical journal The Lancet published a study conducted by British physician Andrew Wakefield that linked the MMR vaccine to the development of autism.6 Further investigation into Wakefield's study, however, exposed the falsification of data among other acts of scientific fraud, and in 2010 The Lancet formally retracted the paper and Wakefield was stripped of his medical license. ${ }^{7}$ Wakefield's now disgraced study has had widespread ramifications on public health, and the negative emotions and fears that it has evoked still persist among parents.

While the claims of an association between vaccinations and disorders like autism are completely unfounded, Dr. Ward acknowledges that vaccines are not $100 \%$ safe. As with any procedure, there are certain risks and side effects associated with vaccines, the most common being local inflammation, malaise, and low-grade fever, all of which typically last a few days. ${ }^{8}$ Although very rare, there are also well-documented cases of severe side effects following vaccination. ${ }^{9}$ A small number of infants developed post-infectious encephalomyelitis from the measles vaccine. ${ }^{10}$ Post-infectious encephalomyelitis is a primary demyelinating disorder of the central nervous system that causes symptoms similar to those observed in multiple sclerosis; it can leave those affected with permanent neurological defects. Dr. Ward explains that the chance of developing post-infectious encephalomyelitis from the 
measles vaccine is about one in one million. However, the media fail to recognize that without the vaccine the chance of developing post-infectious encephalomyelitis from the actual measles disease is three orders of magnitude higher - a nearly one in one thousand risk. "They compare the risk of the vaccine-associated adverse events versus nothing when what they should be doing is comparing [the risks of the vaccineassociated adverse events] versus the risks of the disease."

In addition to concerns regarding vaccination safety, Dr. Ward has noticed that more and more Canadians are refusing vaccines because they simply do not feel that they are at risk for contracting the disease. Most people in this day and age have not seen the consequences of diseases like smallpox or polio and it is perhaps for this reason that they are starting to underestimate the importance of vaccines. Dr. Ward provides the uptake of the influenza vaccine as a prime example of this. Initially, when the influenza vaccine became available, the uptake was very low, and, unfortunately, it was not until people started dying from the flu that people wanted the vaccine. "This is tragic," Dr. Ward comments.

It is critical that we acknowledge the real risks and benefits associated with vaccines and are not swayed by the misuse of statistics in the media that overemphasize the risks associated with vaccines. While vaccines are not perfect, Dr. Ward urges their use, as they are still by far the best tools that we have to protect ourselves from infectious diseases.

Up until now, vaccines have been used as prophylactics intended to prevent diseases. We are now rapidly entering a phase where vaccines are becoming therapeutic. In addition to improving the safety and efficacy of existing vaccines, current researchers are working on developing vaccines with the potential of treating cancer, allergies, substance addiction, and hepatitis $C$. "The next $10-20$ years are going to be very exciting," Dr. Ward adds. In fact, there is already a vaccine for pancreatic cancer being tested in late stage clinical trials that is showing a lot of promise..$^{11}$ The most common side effects associated with this cancer vaccine were flulike symptoms, making it considerably less toxic compared to the radiation therapy that is traditionally used to treat it. Perhaps these exciting discoveries will be the missing piece we need to rebuild the public's confidence in vaccines.

\section{References}

1. CDC.gov. Immunization schedules [Internet]. Atlanta: Center for Disease Control ad Prevention; date of first publication unknown [updated 2014 Jan; cited 2014 Feb]. Available from: http://www.cdc.gov/vaccines/ schedules/easy-to-read/child.html.

2. UNICEF. Child well being in rich countries [Internet]. Florence:Innocenti Research Center; 2013 [updated 2013 Apr; cited 2014 Jan]. Available from: http://www.unicef-irc.org/Report-Card-11.

3. $\mathrm{CBC}$ News. Lethbridge measles outbreak prompts vaccine clinics [Internet]. Calgary: CBC Radio Canada; 2013 Oct 23[updated 2013 Oct 24; cited 2014 Feb 3]. Available from: http://www.cbc.ca/news/canada/calgary/ lethbridge-measles-outbreak-prompts-vaccine-clinics-1.2190840.

4. Atwell JE, Van Otterloo J, Zipprich J, Winter K, Harriman K, Salmon DA, et al. Nonmedical vaccine exemptions and pertussis in California, 2010. Pediatrics. 2013;132(4):624-30.

5. Alphonso C. Whooping cough makes deadly return across Canada. The Globe and Mail [Internet]. 2012 Jul 23 [cited 2014 Feb 8]. Available from: http://www.theglobeandmail.com/life/health-and-fitness/health/ whooping-cough-makes-deadly-return-across-canada/article4436946/.

6. Johnson M. Health Buzz: Autism-vaccine doctor stripped of medical license. US News [Internet]. 2010 May 24 [cited 2014 Feb 5] Available from: http://health.usnews.com/health-nmanaging-your-healthcare/brainand-behavior/articles/2010/05/24/health-buzz-autism-vaccine-doctorstripped-of-medical-license.

7. Eggertson L. Lancet retracts 12 -year-old article linking autism to MMR vaccines. CMAJ: Canadian Medical Association journal = Journal de I'Association Medicale Canadienne. 2010;182(4):E199-200.

8. McCann LJ, Ford KJ, Pollard AJ, Kulkarni R, Amirthalingam G, Smith A, et al. Self-reported adverse events in adolescents aged 13-18 years after mass vaccination with pertussis-containing vaccine, following a school outbreak. Public Health. 2013;127(12):1133-6.

9. Cerpa-Cruz $S$, Paredes-Casillas $P$, Landeros Navarro $E$, Bernard-Medina AG, Martinez-Bonilla G, Gutierrez-Urena S. Adverse events following immunization with vaccines containing adjuvants. Immunologic Research. 2013;56(2-3):299-303.

10. Huynh W, Cordato DJ, Kehdi E, Masters LT, Dedousis C. Post-vaccination encephalomyelitis: Literature review and illustrative case. Journal of Clinical Neuroscience: Official Journal of the Neurosurgical Society of Australasia. 2008;15(12):1315-22.

11. Salman B, Zhou D, Jaffee EM, Edil BH, Zheng L. Vaccine therapy for pancreatic cancer. Oncoimmunology. 2013;2(12):e26662.

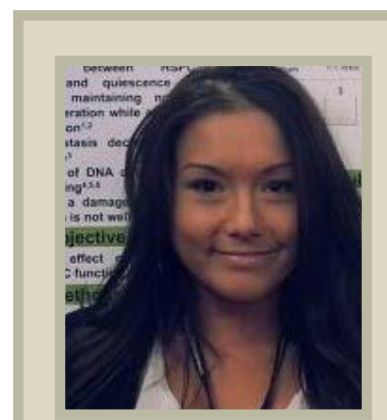

\section{Kelsey O'Hagan-Wong}

Kelsey completed her bachelor's degree at York University and is now finishing her master's degree at McGill University in experimental medicine. Her research examines hematopoietic stem cell and mesenchymal stem cell crosstalk and how this important interaction is affected in rheumatoid arthritis and aging. 